$1 \quad$ Inter-basin water transfers and the expansion of aquatic

\title{
invasive species
}

$4 \quad{ }^{1}$ Department of Biodiversity and Restoration. Pyrenean Institute of Ecology (IPE-CSIC).

$5 \quad$ Avda. Montañana 1005, 50059, Zaragoza (Spain)

$6{ }^{2}$ Department of Zoology, University of Cambridge, The David Attenborough Building,

7 Pembroke Street, Cambridge CB2 3QZ (UK)

$8 \quad *$ Corresponding author: Belinda Gallardo

$9 \quad$ Present address:

10 Applied Ecology \& Restoration Group, Biodiversity and Conservation Department

11 Pyrenean Institute of Ecology (IPE-CSIC). Avda. Montañana 1005, 50059 Zaragoza (Spain)

12 Phone: 0034 976369393; e-mail: belinda@ipe.csic.es; galla82@hotmail.com

13 Running title: Water transfers promote biological invasions 


\section{Abstract}

15 Inter-basin Water Transfers (IBWT) are recognized as one of the major pathways of freshwater

16 invasion. They provide a direct link between previously isolated catchments and may modify

17 the habitat conditions of the receiving waters such that they become more favourable for the

18 establishment of invasive species. Combined, IBWT and invasive species will intensify the

19 stress upon native species and ecosystems. Using the Severn and Thames Rivers -two of the

20 largest river systems in Great Britain - as a case study, here we assess the potential influence

21 of IBWT on the expansion of invasive species and thus their impact on biodiversity

22 conservation. The Thames Valley is subject to extensive water abstraction, and an increasing

23 population means that supplemented flow from the River Severn is being considered. Multi-

24 scale Suitability Models, based on climate and water chemistry respectively, provided novel

25 evidence that there is serious risk for further spread of invasive species in the focus area,

26 particularly of the quagga mussel, a recent invader of the Thames River. Native freshwater

27 mussels are particularly vulnerable to changing environmental conditions, and may suffer the

28 decrease in alkalinity and increase in sedimentation associated with an IBWT from the lower

29 Severn to the upper Thames. Regional models suggest considerable overlap between the areas

30 suitable for three vulnerable native freshwater mussels and the expansion of invasive species

31 that negatively impact upon the native mussels. This study illustrates the use of novel spatially-

32 explicit techniques to help managers make informed decisions about the risks associated with

33 introducing aquatic invasive species under different engineering scenarios. Such information

34 may be especially important under new legislation (e.g. EU Invasive Species Regulation No

$351143 / 2014)$ which increases the responsibility of water managers to contain and not transfer

36 invasive species into new locations. 
37 Keywords: quagga mussel; exotic species; species distribution models; landscape connectivity analysis; climate change; water engineering;

\section{Introduction}

Climate change is currently prompting water-engineering responses in anticipation of greater frequency of floods and droughts that will not only threaten water security but also freshwater biodiversity (Vörösmarty et al. 2010). Inter-Basin Water Transfers (IBWT) modify the water flow, chemistry and temperature of receiving waters, affecting the composition, abundance, richness and distribution of aquatic communities (Bunn and Arthington 2002). In fact, IBWTs are recognized as one of the major pathways of freshwater invasion in Europe (Jażdżewski 1980, Leuven et al. 2009). First, IBWTs provide a direct link between previously isolated catchments (Gupta and van der Zaag 2008). For example, the once isolated rivers draining the Caspian and Black Seas became inter-connected through canal construction in the

$5020^{\text {th }}$ century, facilitating the spread of Ponto-Caspian invasive species into western Europe (e.g.

51 Rhine-Danube-Main waterways, Leuven et al. 2009). Interconnectivity of waterways has 52 consequently removed major biogeographic barriers, leading to a situation where distant 53 rivers share a high proportion of their (invasive) flora and fauna (Galil et al. 2007). Further, 54 IBWTs modify the habitat conditions of the receiving waters, changes that often favour the 55 establishment of invasive species (Dudgeon et al. 2006). For instance, increased alkalinity and temperature are known to provide a competitive advantage to invasive species over their native counterparts (Gallardo and Aldridge 2013c, Grabowski et al. 2009, Paillex et al. 2017). The compounded deleterious effects of water transfers and invasive species will intensify the stress upon native species, with the potential to ultimately provoke local extinctions (O'keeffe 
and De Moor 1988). For instance, the Tajo-Segura IBWT (SW Spain) operating since 1978, promoted the invasion of at least 13 invasive fish and one mollusc (Oliva-Paterna et al. 2014, Zamora-Marín et al. 2018), which resulted in $40 \%$ of native species threatened with local extinction (Oliva-Paterna et al. 2014).

To illustrate the potential influence of IBWTs on the expansion of invasive species and thus their impact on biodiversity conservation, here we use the catchments of the River Severn and River Thames as a case study (Fig. 1). Representing the two largest rivers in Great Britain, they collectively supply drinking water to 35 million people ( $>50 \%$ GB population). Climate simulations in Great Britain predict substantial reductions in summer precipitation accompanied by increased evapotranspiration throughout the year, leading to reduced flows in the Thames River in late summer and autumn (Diaz-Nieto and Wilby 2005). Water transfers from the nearby Severn River have long been suggested as an adaptation strategy to ensure the water supply of the Thames region (Jamieson and Fedra 1996, Rodda 2006). The SevernThames IBWT could arguably modify the river flow, hydrodynamics and water quality conditions of both rivers, the conservation of freshwater and terrestrial protected sites near the abstraction and discharge points as well as along the transfer route, and the movement of migratory fish (Bunn and Arthington 2002). Furthermore, the River Thames is one of the greatest hotspots of aquatic invasive species in the world (Jackson and Grey 2013, Zieritz et al. 2014), including myriad Ponto Caspian invaders with a high potential to spread widely across Great Britain (Gallardo and Aldridge 2015). Consequently, there is a serious risk of an eventual IBWT promoting further expansion of invasive species in the region, which may severely affect the status of vulnerable native biota and the broader ecosystem services of the two rivers. Of particular concern is the depressed river mussel (Pseudanodonta complanata Rossmässler, 1835 ) that has disappeared from over $30 \%$ of its historical sites in Great Britain (Killeen et al. 
84 2004), the duck mussel (Anodonta anatina Linnaeus, 1758), and the painter's mussel (Unio

85 pictorum Linnaeus, 1758). The conservation of all three molluscs is a concern throughout

86 Europe (Lopes-Lima et al. 2017). They are especially vulnerable to fouling from invasive zebra

87 mussels (Dreissena polymorpha Pallas 1771) and quagga mussels (Dreissena rostriformis

88 bugensis Andrusov 1897), and competition for habitat and resources with Asian clams

89 (Corbicula fluminea O. F. Müller, 1774), all of which are present within the region (Aldridge et

90 al., 2004; Sousa et al, 2011).

This study investigates: i) the climate suitability for three high-risk aquatic invasive species,

92 ii) the most likely pathways of spread between catchments, iii) the environmental suitability (in

93 terms of river geomorphological and physicochemical characteristics) of the focus area to

94 invasive species, and iv) their combined effects upon the conservation of three native species.

95 Ultimately, this study evaluates the collective influence of water transfers on the potential for

96 establishment and spread of invasive species, and their consequences for the conservation of

97 vulnerable freshwater taxa. This information is critical to inform river management in a global

98 change context, particularly under new legislation (e.g. EU Invasive Species Regulation No

$991143 / 2014)$ that increases the responsibility of water managers to contain and avoid

100 transferring invasive species into new locations.

\section{Materials and Methods}

The objectives of this study were achieved using multi-scale Species Distribution Models

103 (SDM). These models are increasingly used to anticipate biosecurity threats associated with

104 climate change and the expansion of invasive species (Jeschke and Strayer 2008). In brief,

105 SDMs correlate the occurrence of a given species with the environmental conditions, usually

106 climatic, of the sites it inhabits in order to locate areas that are most susceptible to invasion 
107 (Guisan and Thuiller 2005). While direct indicators of water conditions (water temperature and 108 river flow) are preferable over indirect climate surrogates (air temperature and precipitation), multiple studies have demonstrated the prominent role of climate over geological (Quinn et al. 2014), hydrological (McGarvey et al. 2017) or socio-economic aspects (Gallardo and Aldridge 2013a) on the distribution of aquatic organisms at the global scale. Climate surrogates are especially useful when modelling invasive species because they allow using information from the entire global range of distribution of invasive species (native and invasive). This is important, because invasive species are rarely in equilibrium with the environment in the invaded range, and using regional information only may seriously underestimate their probability of further expansion. Many examples exist of studies using climate to model the potential distribution of aquatic organisms such as fish (e.g. Chen et al. 2007), aquatic snails (e.g. Loo et al. 2007), shrimps (e.g. Gallardo et al. 2012), crayfish (e.g. Capinha et al. 2012) and mussels (e.g. Drake and Bossenbroek 2004), among others. In addition, climatic factors offer the advantage of future projections that allow exploring the potential trajectories of invasive species, scenarios provided by the IPCC that are not yet available for other environmental or human indicators.

Nevertheless, we are aware that beyond temperature, local factors such as water chemistry and habitat structure are critical to narrow down the water bodies most likely to be invaded (Gallardo and Aldridge 2013c). For this reason, recent studies advocate for the integration of large-scale climate and regional-scale habitat conditions in a two-step modelling approach that makes use of all the available information to investigate the potential distribution of invasive species (Fournier et al. 2017, Gallardo and Aldridge 2013c, Gallien et al. 
131 the preferential corridors between both catchments that could eventually facilitate the

132 expansion of invasive species. Finally, we use regional models to consider local-scale habitat

133 conditions that ultimately determine the species survival, growth, spread and impact. By

134 overlapping suitability maps for invasive and native species, we further identify water bodies

135 where conflicts between native and invasive species are most likely to arise. Outputs from

136 continental and regional SDMs are complementary and together will help evaluate biosecurity

137 issues emerging from the IBWT.

\subsection{Continental Species Distribution Models}

Information on the current global (native and invaded) spatial distribution of the three

invasive (C. fluminea, D. polymorpha and D. r. bugensis) and three native ( $P$. complanata, $A$.

anatina and $U$. pictorum) species was obtained from the following international and regional

data gateways: Global Biodiversity Information Facility (GBIF, http://data.gbif.org), the

National Biodiversity Network (NBN, Gateway http://data.nbn.org.uk), Discover Life

(http://www.discoverlife.org), and complemented with an extensive ISI Web of Knowledge

literature review (see list of references in Gallardo and Aldridge 2013c, Gallardo and Aldridge

2015). The zebra mussel, D. polymorpha, is widely spread across both catchments, whereas $D$.

r. bugensis and C. fluminea are limited to the lower Thames River (Fig. 1). Native species are species can be consulted in Supplementary Materials (Fig. S1).

To investigate the climatic suitability of the focus area to invasive and native species, five global bioclimatic variables plus geographic elevation $(\mathrm{m})$ were obtained from WorldClim 
154 temperature of the coldest month $\left({ }^{\circ} \mathrm{C}\right)$, precipitation of the wettest month $(\mathrm{mm})$, precipitation

155 of the driest month $(\mathrm{mm})$, and precipitation seasonality (coefficient of variation) $(\mathrm{mm})$.

156 Variables were chosen to show correlation $r<|0.7|$, a well-accepted limit for SDM (Gallardo et

157 al. 2017). These bioclimatic variables represent annual trends, seasonality and extremes that

158 are appropriate to explain species survival (Hijmans and Graham 2006) and were thus selected

159 based on their relevance to explain the large scale distribution of species (see Quinn et al.

160 2014). For example, air temperature is directly related to water temperature (Stefan and

161 Preud'homme 1993), which affects the reproduction, growth, dispersal, metabolism and

162 oxygen consumption of aquatic organisms (Griebeler and Seitz 2007, Jacobsen et al. 1997).

163 Rainfall patterns affect the discharge and depth of rivers and lakes and therefore the likelihood

164 of droughts and floods that can have marked effects on freshwater organisms (Nickus et al.

165 2010), although we expect precipitation-related variables to be less important than

166 temperature in the models. We included altitude in our models because the associated high

167 currents and low organic matter can limit the distribution of aquatic molluscs, regardless of

168 temperature (Quinn et al. 2014). For instance, zebra mussels in Europe are rarely found above

$169500 \mathrm{~m}$ (Strayer 1991). We chose a 30 arc-second (approximately $1 \times 1 \mathrm{~km}$ at the equator)

170 resolution for variables used as predictors in SDM, a high resolution that allows the precise

171 characterization of the aquatic species' climate niche (Gallardo et al. 2015). To calibrate SDMs,

172 we used the MaxEnt algorithm, which typically outperforms other methods based on

173 predictive accuracy (Merow et al. 2013). For input, MaxEnt models use the dataset of species

174 occurrences and the set of climatic predictors that might affect the likelihood of species

175 establishment. The following modelling parameters were implemented in software MaxEnt

176 v3.3k: convergence threshold $=100$, maximum iterations $=500$, prevalence $=0.5,10,000$

177 random pseudo-absences. 
To compensate for any potential sampling bias in the species current distribution, we used the Global Accessibility Map produced by the European Commission (http://bioval.jrc.ec.europa.eu/)(Nelson 2008), which measures the travel time needed to access from any pixel to the closest major city (i.e. $>50,000$ inhabitants). This bias indicator outperformed other methods to correct the initial sampling bias of distribution models (Fourcade et al. 2014), and has been used to compensate sampling bias for the modelling of freshwater invasive species in Europe (Gallardo et al. 2017).

A 10-fold cross-validation was used to evaluate the predictive power of the model. This technique splits the occurrence dataset into ten equal-size groups called "folds", and models are created leaving out each fold in turn. The omitted fold is then used for evaluation. Average values from the ten replicates were used for reporting and mapping potential distributions. To assess model performance, the Area Under the Receiving Operating Characteristic (ROC) Curve (AUC) (Hanley and McNeil 1982) was used, which represents the probability that a random occurrence locality is classified as more suitable than a random pseudo-absence. A model that performs no better than random has an AUC of 0.5 , whereas a model with perfect discrimination scores 1.

After calibration, models were projected into the focus area to obtain suitability maps. Suitability is a measure of the match with the climatic conditions of locations currently invaded by a species and ranges from 0 (completely dissimilar) to 1 (perfect match). The threshold maximizing the sensitivity (i.e. number of presences correctly predicted) and specificity (i.e. number of absences correctly predicted) of the model was used to transform suitability maps into binary presence/absence maps. Binary maps allow investigating the full potential of spread of invasive species. By overlapping maps of native and invasive species, we identified regions where conflicts may arise. 
202

203

204

205

206

\subsection{Landscape Connectivity Analysis}

Once suitability maps were obtained for each invasive species, we assessed the most likely natural pathways of dispersal between the two catchments using Landscape Analysis of Connectivity (LAC), a technique commonly used for examining population connectivity across landscapes (Urban et al. 2009). LAC assumes that high habitat suitability implies low cost to the dispersal for a species across a particular region, whereas regions with low suitability have high dispersal costs. Thus, LAC incorporates detailed habitat information as well as species-specific aspects on a measure of connectivity (Adriaensen et al. 2003). This type of modelling tool is receiving growing attention in applied land and species management projects as a powerful approach for predicting population connectivity.

As input, LAC takes a friction layer and a set of "points of interest", that is, the potential source and sink locations of propagules. In the absence of specific points of withdrawal and discharge, we manually located 16 points of interest regularly at $30-\mathrm{km}$ distance along the River Severn $(\mathrm{N}=8$ ) and the River Thames ( $\mathrm{N}=8$ ) (Fig. 1). The inverse of each climate suitability map was used as a friction layer, assuming that the lower the climatic suitability for a particular invader, the higher the habitat resistance or "cost" to its dispersal.

The result of LAC is a map that indicates the routes that would ultimately facilitate the dispersal of invasive species between the eight points of interest located in each catchment and that should thus be avoided by an eventual IBWT. However, we must note that LAC is pertinent for assessing the risk of open-air canals, but irrelevant in cases where water is pumped through underground pipelines. While in this case the risk of invasive species transportation is mostly unknown, we will discuss the risks that our three focus invasive 
224 species may pose to the correct functioning of underground pipes. Friction layers and LAC

225 were calculated using the SDMToolbox implemented in ArcView v.10.2.

226

\subsection{Regional Species Distribution Models}

The same set of invasive and native species was considered for modelling at the regional scale. The only exception was the quagga mussel, $D$. $r$. bugensis, since the information available for Great Britain (with only two presence points in the Wraysbury River, a tributary of the middle Thames) was insufficient to calibrate regional models.

Data on the current presence of both invasive and native species in Great Britain's river networks used for continental models was complemented with information from the National Biodiversity Network (NBN) database (https://nbnatlas.org/), the UK Environment Agency (http://data.gov.uk/), Killeen (2012) and from our own field surveys in the upper Thames (data uploaded to NBN database and tagged to D. Aldridge).

Data on environmental predictors relevant to explain the regional distribution of species were obtained from the UK's Environment Agency (EA) in the form of a shapefile. In this database, each segment in GB's hydrological network is assigned an identification code by the EA, geographic coordinates, and a set of environmental values measured in 2012. The candidate environmental predictors comprised ten variables: alkalinity $(\mathrm{ppm})$, river width $(\mathrm{m})$, river depth $(\mathrm{m})$, altitude $(\mathrm{m})$, slope, substrate structure (\% of boulders and pebbles, sand, silt and clay), discharge $\left(\mathrm{m}^{3} / \mathrm{s}\right.$ ), and ecological status (four categories: bad, moderate, good, not yet analysed) (see maps in Fig. S2). Such detailed river segment information is not available at larger continental to global scales, and for this reason could not be incorporated into continental models. 
Regional distribution models were calibrated with MaxEnt v3.3k using the Samples With

247 Data (SWD) option (Elith et al. 2010). Model settings (10-fold cross-replication), evaluation (by

248 AUC) and mapping followed those described for continental SDM. Response curves provided

249 by MaxEnt were used to investigate the influence of environmental variables likely to change

250 after a water transfer such as alkalinity, discharge and the river substrate, on the

251 establishment of invasive species and the survival of native species. Suitability maps for the

252 three invasive and three native species were cross-compared to evaluate the potential for

253 interaction between invasive and native species.

\section{Results}

Models calibrated with the global occurrence of invasive and native species and a set of

climatic predictors showed a high accuracy (test AUC between 0.87 and 0.98 , Table S1). The

most important variables contributing to the models were minimum ( $48 \%$ on average) and

maximum (22\%) annual temperatures (Table S1).

Suitability maps presented in Figure 2 suggest a high potential for further spread of $C$.

fluminea and D. r. bugensis, showing highest risk scores in the lower Thames River (Figs. 2C

and $2 \mathrm{E}$ ). While the zebra mussel, $D$. polymorpha, is widely established, models suggest it is

likely to keep expanding in both catchments (Fig. 2A). According to the Landscape Analysis of

263 Connectivity (LAC), the connection between the middle course of the Severn (point 5) and

264 Thames (point 10) offers the most suitable corridor for the spread of D. polymorpha (Fig. 2B).

265 The other two invaders, C. fluminea and D. r. bugensis, show preference for the main river

266 channels and the connection between the upper Severn (point 7) and upper Thames (points 9

267 and 10) (Figs. $2 \mathrm{D}$ and F). 
Only the upper part of the Severn River (point 8) is suitable to the three invaders (Fig. 3A), are highly vulnerable to invasion (Fig. $3 \mathrm{~A}$ ). Figure $3 \mathrm{C}$ shows potential areas of conflict with native species, which should be avoided by an IBWT to limit biosecurity threats. This map highlights the potential of the Severn catchment to offer refugia for the conservation of native molluscs (Fig. 3B), because the suitability for invasive species is concentrated in coastal areas and the lower valleys.

The geomorphological and physicochemical conditions of the Severn and Thames Rivers significantly differ (Table 1). The Severn waters have lower alkalinity and proportion of sand, but higher discharge than those of the Thames. Also, the ecological status of the Severn River is predominantly "Moderate" as opposed to "Poor" in the Thames (Table 1). 0.72 and 0.83 , Table S2). Altitude, slope, ecological status and alkalinity were the most important factors explaining the distribution of invasive species; whereas substrate size $(\%$ pebbles, boulders and sand) and alkalinity determined the presence of native molluscs (Fig. 4A). Generally, invaders showed preference for lowland rivers, with Bad to Moderate ecological status, sand-dominated substrate (>20\%) and high alkalinity (>120 mg/L) (Fig. S3). Similar to their invasive counterparts, native species showed preference for lowland rivers,

286 with slow river discharges $\left(<20 \mathrm{~m}^{3} / \mathrm{s}\right)$, gentle slope, high alkalinity ( $\left.>200 \mathrm{mg} / \mathrm{L}\right)$ and high percentage of sand, silt and clay (Fig. S4). The regional heat-map on Figure $4 \mathrm{~B}$ and $4 \mathrm{C}$ reflects the number of invasive species that could eventually find suitable environmental conditions catchments. 


\section{Discussion}

292

\subsection{Multi-scale risk assessment of invasive species}

This study illustrates the use of species distribution models at multiple scales to evaluate the joint threat posed by an inter-basin water transfer and the concurrent expansion of invasive species upon the conservation of native freshwater vulnerable taxa. Multi-scale suitability models enabled us to assess the importance of different aspects of the process of invasion: establishment (climate and water chemistry suitability), spread (least-cost corridors) and impact (overlap with vulnerable native species).

\subsection{Influence of climate on river invasibility}

Based on climate suitability, the invasive species with the highest potential for spread in the study area is the quagga mussel, D. r. bugensis. Native from the Ponto Caspian region, the quagga mussel's first British record was the Wraysbury River, a tributary of the middle Thames, in September 2014 (Aldridge et al. 2014), confirming previous risk assessments pointing to this mussel as the highest threat to British waters (Gallardo and Aldridge 2013d, Gallardo and Aldridge 2015, Roy et al. 2014). Latest investigations suggest that the species is spreading quickly, and that it may establish widely across England, west and southern Wales, and central Scotland (Gallardo and Aldridge 2015). According to our study, the suitability for this invader is highest in the middle-lower Thames and passive spread can allow rapid spread to downstream locations. For instance, Asian clams colonized the main channel of the Segura River (SW Spain) after the transfer with the Tajo River, and rapidly expanded downstream through passive drift (Zamora-Marín et al. 2018). 
Most aquatic organisms are ectothermic and thus temperature is important in their physiology, bioenergetics, behaviour and biogeography (Jacobsen et al. 1997, Rahel and Olden 2008). Reflecting this, our models showed that minimum monthly temperature explained on average $48 \%$ of the distribution of invasive species, with low probability of establishment at values below freezing $\left(0^{\circ} \mathrm{C}\right)$. For this reason, we may expect climate change to shift the climatic conditions of the focus area closer to the invaders' optima. This may not only affect their probability of establishment, abundance, and distribution, but also their per capita effects (Hellmann et al. 2008, Rahel and Olden 2008), thereby increasing the stress upon native communities (lacarella et al. 2015).

\subsection{Potential corridors between catchments}

Using suitability as a friction layer, LAC allowed identification of the least-cost corridors between the lower Severn and upper Thames Rivers. A particularly high-risk route for a transfer would be an open-air canal from the upper Severn at point 7 to the upper Thames at point 9. This could result in the transfer of zebra mussels from the Severn to locations in the introductions of invasive species are limited. Corridors may not only accelerate the expansion of invasive species, but also the genetic mixing of populations established in both rivers, 
335 already documented in the Segura River after the transfer from the Tajo (Oliva-Paterna et al.

336 2014)

The biosecurity risks posed by an eventual IBWT are high, but results from our LAC models

only apply to open-air canals and not necessarily to the underground pipes that could alternatively connect the two rivers. Factors affecting the capacity of invaders to survive or even establish in underwater pipelines are not currently known. However, the three invasive species investigated here are important biofoulers known to affect irrigation systems (Rosa et al. 2011), and water treatment facilities (Elliott et al. 2005), causing multimillion losses in cleaning and maintenance (Oreska and Aldridge 2011). One of the main problems related to the presence of biofoulers is the clogging of pipelines, which reduces the water flow and often ceases irrigation. As a result, much more frequent cleaning is necessary. For instance, in the irrigation system fed by Mondego River (Portugal), several tonnes of Asian clams are removed from the canal in each of the cleaning routines taking place after the arrival of the species in 2005 (Rosa et al. 2011). To avoid such infestations, the Severn-Thames transfer scheme should plan effective measures to prevent the colonization of underground pipelines by biofoulers. This could include, whenever possible, operating transfers outside the breeding season of the mussels to prevent transfer of planktonic veliger larvae, or allowing pipelines to dry out between transfers so that biofouling communities cannot establish. Control of invasive bivalves within transfer systems could be achieved using approved, targeted, degradable technologies such as microencapsulated BioBullets (Aldridge et al. 2006). 
359 for aquatic invasion (Carlton 1993). For instance, while 13 invasive fish were documented 360 shortly after the Tajo-Segura connection was established, it is difficult to ascertain whether fish 361 arrived through the new connection, or were intentionally introduced by fisherman in the 362 associated reservoirs (Oliva-Paterna et al. 2014). An increase in propagule pressure, even in a 363 populated catchment like the Thames, is not trivial, since this is the most consistent determinant of the establishment success of invasive species (Cassey et al. 2018). Furthermore, despite high habitat suitability along much of its length, invasive species are currently concentrated in the lower sections of the Thames River (except the zebra mussel, Fig.

2). This suggests that increased propagule pressure could facilitate further invasion into the upper-middle sections of the Thames and Severn Rivers.

\subsection{Influence of water chemistry on river invasibility}

At the regional scale, invaders showed preference for lowland rivers, with sandy substrate, and high alkalinity (>120 mg/L). Alkalinity reflects the availability of $\mathrm{CaCO}_{3}$ in water and therefore affects the formation of mussel shells (Greenaway 1985). For this reason, the quagga and zebra mussels colonize more frequently waters with relatively high alkalinity (Gallardo and Aldridge 2013c); a requirement that may explain the lower establishment of Ponto Caspian invaders in tributaries that usually register lower alkalinity than the main river channel (Grabowski et al. 2009). Remarkably, invasive species were more likely to occur in waterbodies with a Bad to Moderate ecological status, than in sites with a Good ecological status as defined by the UK Environment Agency, often based on invertebrate indicators. It is logical to expect a

379 higher propagule pressure in waterbodies that are affected by various human activities and

380 therefore show poor ecological status. Moreover, disturbance from human activities may 381 especially favour the establishment of freshwater invasive species (Paillex et al. 2015). This 382 observation could also suggest certain "biotic resistance" of well-preserved ecosystems to the 
383 colonization of invasive species, a process with mixed support in the literature (see Jeschke et 384 al. 2012 for a review). If a relation between ecological status and either propagule pressure or 385 actual invasion levels is confirmed, then promoting the ecological conservation of freshwaters 386 may help prevent the spread of invaders. Conversely, sites with poor ecological status may be 387 especially vulnerable through the facilitative interactions of invasive species which can lead to an "invasional meltdown" (Gallardo \& Aldridge, 2015).

Potential changes in the Thames River water chemistry after an eventual IBWT include a decrease of alkalinity, and increase of siltation and discharge. While invasive species have preference for high alkalinity (Gallardo and Aldridge 2013c), the IBWT is unlikely to affect established populations of invasive species that are normally tolerant to a broad range of conditions. The three invasive species evaluated require $>20 \%$ silt and clay substrate to colonize, with decreasing suitability at increasing sand and boulders coverage (Fig. S3). species in the upper Thames, where the percentage of silt and clay tend to be low. The effect of increasing river discharge is difficult to anticipate. Some invaders such as the Asian clam show preference for low discharge $\left(<5 \mathrm{~m}^{3} / \mathrm{s}\right.$ according to our database) and may be negatively affected by a potential increase in flow. Nonetheless, considering the low discharge of the Thames River (0.6-1.2 $\mathrm{m}^{3} / \mathrm{s}$, Table 1$)$, the water transfer is unlikely to affect the distribution of invaders in the study area. 


\subsection{Collective impacts on native species}

According to our maps, most of the focus area offers suitable environmental conditions to the establishment of the three native mussels (Figs. 3 and 4), and yet they are not usually found in the upper parts of rivers. This can be attributed primarily to the dietary requirements of unionid mussels that are collectors, requiring a relatively high level of particulate organic matter in suspension. Supplementation of flow in the upper Thames through an IBWT from the lower Severn may encourage native mussels to establish further upstream in the Thames. However, other aspects of such an IBWT could be harmful to the native mussels such as a decrease in alkalinity and increase in sedimentation, which is especially harmful to the depressed river mussel (Killeen et al., 2004). Furthermore, native freshwater mussels are particularly sensitive to river management operations (Mclvor and Aldridge 2007), and may severely suffer the consequences of any water transfer between the Severn and the Thames Rivers.

In addition to the IBWT, climate warming may strongly affect the survival, growth and reproduction success of native mussels (Aldridge 1999, Mclvor and Aldridge 2007). For instance in the Saone River (France), a $1.5^{\circ} \mathrm{C}$ increase in temperature resulted in a progressive change in freshwater mollusc communities, a decrease in species abundance, and richness (Mouthon and Daufresne 2010). Such changes in community structure usually lead to changes in important ecosystem functions such as nutrient cycling and benthic-pelagic coupling (Spooner and Vaughn 2008). Maximum temperature tolerance for the three native mussels are not known, but studies suggest that this limit is usually higher for invasive than native mussels, implying that global warming will disproportionally affect native species (Verbrugge et al. 2012). Further, differential effects of temperature in freshwater mussels and their fish hosts may cause problems by uncoupling the timing of mussels and fish reproduction as well as 
431 changes in overall fish host availability (Hastie et al. 2003). This is not the case of invasive

432 mussels such as the Asian clam or zebra and quagga mussels that reproduce via planktonic

433 larvae, and this may further increase the competitiveness of invasive mussels under a climate

434 change scenario (Gallardo and Aldridge 2013b).

There is little evidence about the impacts of the quagga mussel upon the UK's native

436 mussel populations, but we can expect them to be similar to the zebra mussels' or even

437 greater, since the quagga is able to colonize sites currently unreachable by the zebra mussel

438 (Higgins and Zanden 2010). In particular, zebra mussels are known to impede the correct

439 opening and closure of the valves of native mussels, to hamper their movement and

440 burrowing, and to directly compete for space and resources (Karatayev et al. 1997). The

441 expansion of the quagga mussel in the River Thames and its potential arrival to the Severn

442 therefore represents a serious threat to the conservation of native freshwater mussels. Finally,

443 engineering works associated to an eventual IBWT may exacerbate this problem (Mclvor and

444 Aldridge 2007) and cause considerable habitat degradation and mussel mortality downstream

445 of the discharge points in the Thames River.

$446 \quad 4.6$ Study limitations and applicability

447 Spatially-explicit techniques such as SDM and LAC have seen considerable application for

448 land and species management, and yet they have been rarely used to model aquatic

449 ecosystems. This is probably because aquatic information is often available as vector (point or

450 segment) rather than raster (gridded) format. Here we have illustrated the application of

451 spatially explicit techniques combining the available information at global and regional scales.

452 Nevertheless, we must bear in mind that models have been calibrated using a (limited)

453 number of predictors and that other missing factors (e.g. interaction with native species,

454 microhabitat and food availability, barriers to dispersal, habitat disturbance) may affect the 
455 ultimate spread and successful establishment of invaders as well as the survival of native

456 species. In addition, models reflect suitability, that is, probabilities of invasion in the event of

457 an introduction, and not absolute survival limits. A high suitability does not necessarily mean

458 the species will establish, but simply that conditions are suitable for this event. Since

459 colonization of the upper section of rivers is often dispersal-limited, special attention should

460 be paid to the introduction of propagules by means of engineering works associated with

461 IBWT. Ultimately, this case study illustrates how SDM can broadly help anticipate the

462 expansion of multiple potential invaders, thereby enabling informed prioritisation of limited

463 resources to guide monitoring, management and control decisions.

\section{Conclusions}

- Inter-Basin Water Transfers may promote the expansion of aquatic invasive species. An

IBWT can increase propagule pressure to recipient regions, change habitat conditions canals, embankments and reservoirs that promote water-related activities (boating, shipping or fishing) and that are important vectors for aquatic invasion.

- The invasive species with the highest potential for spread in the Thames and Severn Rivers is the quagga mussel, D. r. bugensis. The species is currently limited to one location in the Thames, but shows high climate suitability in the study area. Quagga mussels may be able to colonize sites currently unreachable by the zebra mussel and therefore represent a serious threat to the conservation of native freshwater mussels. Quagga and zebra mussels may establish further upstream if IBWT leads to increased water depth and higher turbidity.

- Climate change may exacerbate the risks associated to an IBWT. Climate change will shift the climatic conditions of the focus area closer to the invaders' optima thereby 

hosts.

- Native species will suffer the concurrent effects of habitat degradation, the arrival of invasive species and climate change. Aspects of an IBWT harmful to the native mussels include a decline in alkalinity, increase in sedimentation, and river management operations that intensify the stress upon native mussels. The IBWT jeopardizes the potential role of the Severn River as refuge for the conservation of native mussels. open-air canal from the upper Severn to the upper Thames. Since colonization of the upper section of both rivers is dispersal-limited, special attention should be paid to the introduction of propagules by means of engineering works that can cause considerable habitat degradation and native mussel mortality. The potential transfer of invasive species through IBWTs could be reduced by operating transfers outside their reproductive season so that planktonic larvae are not transported. Fouling of transfer systems may be reduced through operating the transfer sporadically thus allowing the pipeline to periodically run dry. 
analyses. BG and DCA wrote the manuscript.

\section{Acknowledgements}

BG was funded by a Juan de la Cierva fellowship by the Spanish Ministry of Economy (JCl-

2012-11908). DCA was supported by a Dawson Lectureship from St. Catharine's College,

506 Cambridge. The main author is grateful for the technical assistance of Manuel Pizarro (IPE-

507 CSIC), in this investigation.

\section{References}

Adriaensen, F., Chardon, J., De Blust, G., Swinnen, E., Villalba, S., Gulinck, H. and Matthysen, E.

510 (2003) The application of 'least-cost'modelling as a functional landscape model. Landscape and 511 urban planning 64(4), 233-247.

512 Aldridge, D.C. (1999) The morphology, growth and reproduction of Unionidae (Bivalvia) in a 513 fenland waterway. Journal of Molluscan Studies 65, 47-60.

514 Aldridge, D.C., Elliott, P. and Moggridge, G. (2006) Microencapsulated BioBullets for the 515 control of biofouling zebra mussels. Environmental science \& technology 40(3), 975-979.

516 Aldridge, D.C., Ho, S. and Froufe, E. (2014) The Ponto-Caspian quagga mussel, Dreissena

517 rostriformis bugensis (Andrusov, 1897), invades Great Britain. Aquatic Invasions 9(4), 529-535.

518 Bunn, S.E. and Arthington, A.H. (2002) Basic principles and ecological consequences of altered 519 flow regimes for aquatic biodiversity. Environmental Management 30(4), 492-507.

520 Capinha, C., Anastácio, P. and Tenedório, J. (2012) Predicting the impact of climate change on 521 the invasive decapods of the lberian inland waters: an assessment of reliability. Biological 522 Invasions 14(8), 1737-1751.

523 Carlton, J.T. (1993) Zebra mussels:biology, impacts, and control. Nalepa, T.F. and Schloesser, 524 D.W. (eds), pp. 677-697, CRC Press, Boca Raton (Florida).

525 Cassey, P., Delean, S., Lockwood, J.L., Sadowski, J. and Blackburn, T.M. (2018) Dissecting the 526 null model for biological invasions: A meta-analysis of the propagule pressure effect. PLOS 527 Biology 16(4), e2005987.

528 Chen, P.F., Wiley, E.O. and Mcnyset, K.M. (2007) Ecological niche modeling as a predictive tool: 529 silver and bighead carps in North America. Biological Invasions 9(1), 43-51. 
530 Diaz-Nieto, J. and Wilby, R.L. (2005) A comparison of statistical downscaling and climate 531 change factor methods: impacts on low flows in the River Thames, United Kingdom. Climatic 532 Change 69(2), 245-268.

533 Drake, J.M. and Bossenbroek, J.M. (2004) The potential distribution of zebra mussels in the 534 United States. Bioscience 54(10), 931-941.

535 Dudgeon, D., Arthington, A.H., Gessner, M.O., Kawabata, Z.I., Knowler, D.J., Lévêque, C., 536 Naiman, R.J., Prieur-Richard, A.H., Soto, D. and Stiassny, M.L. (2006) Freshwater biodiversity: 537 importance, threats, status and conservation challenges. Biological Reviews 81(2), 163-182.

538 Elith, J., Phillips, S.J., Hastie, T., Dudík, M., Chee, Y.E. and Yates, C.J. (2010) A statistical 539 explanation of MaxEnt for ecologists. Diversity and Distributions 17(1), 43-57.

540 Elliott, P., Aldridge, D., Moggridge, G.D. and Chipps, M. (2005) The increasing effects of zebra 541 mussels on water installations in England. Water and Environment Journal 19(4), 367-375.

542 Facon, B., Pointier, J.P., Jarne, P., Sarda, V. and David, P. (2008) High genetic variance in life543 history strategies within invasive populations by way of multiple introductions. Current Biology 544 18(5), 363-367.

545 Fourcade, Y., Engler, J.O., Rödder, D. and Secondi, J. (2014) Mapping species distributions with 546 MAXENT using a geographically biased sample of presence data: A performance assessment of 547 methods for correcting sampling bias. Plos One 9(5), e97122.

548 Fournier, A., Barbet-Massin, M., Rome, Q. and Courchamp, F. (2017) Predicting species 549 distribution combining multi-scale drivers. Global Ecology and Conservation 12, 215-226.

550 Galil, B.S., Nehring, S. and Panov, V. (2007) Biological Invasions, pp. 59-74, Springer.

551 Gallardo, B. and Aldridge, D.C. (2013a) The 'dirty dozen': socio-economic factors amplify the 552 invasion potential of 12 high risk aquatic invasive species in Great Britain and Ireland. Journal 553 of Applied Ecology 50(3), 757-766.

554 Gallardo, B. and Aldridge, D.C. (2013b) Evaluating the combined threat of climate change and 555 biological invasions on endangered species. Biological Conservation 160, 225-233.

556 Gallardo, B. and Aldridge, D.C. (2013c) Priority setting for invasive species management: 557 integrated risk assessment of multiple Ponto Caspian invasive species into Great Britain. 558 Ecological Applications 23(2), 352-364.

559 Gallardo, B. and Aldridge, D.C. (2013d) Review of the ecological impact and invasion potential 560 of Ponto Caspian invaders in Great Britain, p. 120, Cambridge (UK).

561 Gallardo, B. and Aldridge, D.C. (2015) Is Great Britain heading for a Ponto-Caspian invasional 562 meltdown? Journal of Applied Ecology 52(1), 41-49.

563 Gallardo, B., Aldridge, D.C., González-Moreno, P., Pergl, J., Pizarro, M., Pyšek, P., Thuiller, W., 564 Yesson, C. and Vilà, M. (2017) Protected areas offer refuge from invasive species spreading 565 under climate change. Global Change Biology 23(12), 5331-5343. 
566 Gallardo, B., Errea, M. and Aldridge, D.C. (2012) Application of bioclimatic models coupled with 567 network analysis for risk assessment of the killer shrimp, Dikerogammarus villosus, in Great 568 Britain. Biological Invasions 14, 1265-1278.

569 Gallardo, B., Zieritz, A. and Aldridge, D.C. (2015) The importance of the human footprint in 570 shaping the global distribution of terrestrial, freshwater and marine invaders. Plos One 10(5), 571 e0125801.

572 Gallien, L., Douzet, R., Pratte, S., Zimmermann, N.E. and Thuiller, W. (2012) Invasive species 573 distribution models - how violating the equilibrium assumption can create new insights. Global 574 Ecology and Biogeography 21(11), 1126-1136.

575 Grabowski, M., Bacela, K., Konopacka, A. and Jazdzewski, K. (2009) Salinity-related distribution 576 of alien amphipods in rivers provides refugia for native species. Biological Invasions 11(9), $577 \quad 2107-2117$.

578 Greenaway, P. (1985) Calcium balance and moulting in the crustacea. Biological Reviews 60(3), $579 \quad 425-454$.

580 Griebeler, E.M. and Seitz, A. (2007) Effects of increasing temperatures on population dynamics 581 of the zebra mussel, Dreissena polymorpha: implications from an individual-based model.

582 Oecologia 151(3), 530-543.

583 Guisan, A. and Thuiller, W. (2005) Predicting species distribution: offering more than simple 584 habitat models. Ecology letters 8(9), 993-1009.

585 Gupta, J. and van der Zaag, P. (2008) Interbasin water transfers and integrated water resources 586 management: Where engineering, science and politics interlock. Physics and Chemistry of the 587 Earth, Parts A/B/C 33(1), 28-40.

588 Hanley, J.A. and McNeil, B.J. (1982) The meaning and use of the Area Under a Receiver 589 Operating Characteristic (ROC) curve. Radiology 1, 29-36.

590 Hastie, L.C., Cosgrove, P.J., Ellis, N. and Gaywood, M.J. (2003) The threat of climate change to 591 freshwater pearl mussel populations. Ambio 32(1), 40-46.

592 Hellmann, J.J., Byers, J.E., Bierwagen, B.G. and Dukes, J.S. (2008) Five potential consequences

593 of climate change for invasive species. Conservation Biology 22(3), 534-543.

594 Higgins, S.N. and Zanden, M.J.V. (2010) What a difference a species makes: a meta-analysis of 595 dreissenid mussel impacts on freshwater ecosystems. Ecological Monographs 80(2), 179-196.

596 Hijmans, R.J. and Graham, C.H. (2006) The ability of climate envelope models to predict the 597 effect of climate change on species distributions. Global Change Biology 12(12), 2272-2281.

598 lacarella, J.C., Dick, J.T.A., Alexander, M.E. and Ricciardi, A. (2015) Ecological impacts of 599 invasive alien species along temperature gradients: testing the role of environmental 600 matching. Ecological Applications 25(3), 706-716. 
601 Jackson, M.C. and Grey, J. (2013) Accelerating rates of freshwater invasions in the catchment

602 of the River Thames. Biological Invasions 15(5), 945-951.

603 Jacobsen, D., Schultz, R. and Encalada, A. (1997) Structure and diversity of stream invertebrate 604 assemblages: the influence of temperature with altitude and latitude. Freshwater Biology $60538(2), 247-261$.

606 Jamieson, D. and Fedra, K. (1996) The 'WaterWare'decision-support system for river-basin 607 planning. 3. Example applications. Journal of Hydrology 177(3-4), 199-211.

Jażdżewski, K. (1980) Crustaceana. Supplement, pp. 84-107, BRILL.

Jeschke, J., Gómez Aparicio, L., Haider, S., Heger, T., Lortie, C., Pyšek, P. and Strayer, D. (2012)

610 Support for major hypotheses in invasion biology is uneven and declining. NeoBiota 14(0), 1-

61120.

612 Jeschke, J.M. and Strayer, D.L. (2008) Usefulness of bioclimatic models for studying climate 613 change and invasive species. Year in Ecology and Conservation Biology 2008 1134, 1-24.

614 Karatayev, A.Y., Burlakova, L.E. and Padilla, D.K. (1997) The effects of Dreissena polymorpha 615 (Pallas) invasion on aquatic communities in eastern Europe. Journal of Shellfish Research 16(1), $616 \quad 187-203$.

617 Killeen, I., Aldridge, D.C. and Oliver, P.G. (2004) Freshwater bivalves of Britain and Ireland, FSC 618 Publications, Shresbury, UK.

619 Killeen, I.J. (2012) A survey for the depressed river mussel Pseudanodonta complanata and 620 other freshwater (unionid) mussels in the River Thames, p. 32, Malacological services for the 621 UK Environment Agency.

622 Leuven, R., van der Velde, G., Baijens, I., Snijders, J., van der Zwart, C., Lenders, H.J.R. and de

623 Vaate, A.B. (2009) The River Rhine: a global highway for dispersal of aquatic invasive species.

624 Biological Invasions 11(9), 1989-2008.

625 Loo, S.E., Mac Nally, R. and Lake, P.S. (2007) Forecasting New Zealand mudsnail invasion range:

626 Model comparisons using native and invaded ranges. Ecological Applications 17(1), 181-189.

627 Lopes-Lima, M., Sousa, R., Geist, J., Aldridge, D.C., Araujo, R., Bergengren, J., Bespalaya, Y., 628 Bódis, E., Burlakova, L. and Van Damme, D. (2017) Conservation status of freshwater mussels 629 in Europe: state of the art and future challenges. Biological Reviews 92(1), 572-607.

630 McGarvey, D.J., Menon, M., Woods, T., Tassone, S., Reese, J., Vergamini, M. and Kellogg, E. 631 (2017) On the use of climate covariates in aquatic species distribution models: are we at risk of 632 throwing the baby out? Ecography 41(4), 695-712.

633 Mclvor, A.L. and Aldridge, D.C. (2007) The reproductive biology of the depressed river mussel, 634 Pseudanodonta complanata (Bivalvia: Unionidae), with implications for its conservation 635 Journal of Molluscan Studies 73, 259-266. 
636 Merow, C., Smith, M.J. and Silander, J.A. (2013) A practical guide to MaxEnt for modeling

637 species' distributions: what it does, and why inputs and settings matter. Ecography 36(10),

$638 \quad 1058-1069$.

639 Mouthon, J. and Daufresne, M. (2010) Long-term changes in mollusc communities of the

640 Ognon river (France) over a 30-year period. Fundamental and Applied Limnology/Archiv für

641 Hydrobiologie 178(1), 67-79.

642 Nelson, A. (2008) Travel time to major cities: a global map of accessibility. Global Environment

643 Monitoring Unit - Joint Research Centre of the European Commission,

644 http://forobs.jrc.ec.europa.eu/products/gam/.

645 Nickus, U., Bishop, K., Erlandsson, M., Evans, C.D., Forsius, M., Laudon, H., Livingstone, D.M., 646 Monteith, D. and RThies, H. (2010) Climate change impacts on freshwater ecosystems. Kernan, 647 M., Battarbee, R.W. and Moss, B. (eds), pp. 38-64, Blackwell Publishing Ltd., Oxford, UK.

648 O'keeffe, J. and De Moor, F. (1988) Changes in the physico-chemistry and benthic 649 invertebrates of the great fish river, South Africa, following an interbasin transfer of water. 650 Regulated Rivers: Research \& Management 2(1), 39-55.

651 Oliva-Paterna, F.J., Verdiell-Cubedo, D., Ruiz-Navarro, A. and Torralva, M. (2014) La ictiofauna 652 continental de la Cuenca del río Segura (SE Península Ibérica): décadas después de Mas 653 (1986)/The freshwater ichthyofauna of the Segura river basin (SE Iberina Peninsula): decades 654 after Mas (1986), p. 37, Servicio de Publicaciones, Universidad de Murcia.

655 Oreska, M. and Aldridge, D.C. (2011) Estimating the financial costs of freshwater invasive 656 species in Great Britain: a standardized approach to invasive species costing. Biological 657 Invasions 13(2), 305-319.

658 Paillex, A., Castella, E., zu Ermgassen, P., Gallardo, B. and Aldridge, D.C. (2017) Large river 659 floodplain as a natural laboratory: non-native macroinvertebrates benefit from elevated 660 temperatures. Ecosphere 8(10), e01972.

661 Paillex, A., Castella, E., zu Ermgassen, P.S.E. and Aldridge, D.C. (2015) Testing predictions of 662 changes in alien and native macroinvertebrate communities and their interaction after the 663 restoration of a large river floodplain (French Rhône). Freshwater Biology 60(6), 1162-1175.

664 Quinn, A., Gallardo, B. and Aldridge, D.C. (2014) Quantifying the ecological niche overlap 665 between two interacting invasive species: the zebra mussel (Dreissena polymorpha) and the 666 quagga mussel (D. rostriformis bugensis). Aquatic Conservation: Marine and Freshwater 667 Ecosystems 24, 324-337.

668 Rahel, F.J. and Olden, J.D. (2008) Assessing the effects of climate change on aquatic invasive 669 species. Conservation Biology 22(3), 521-533.

670 Rodda, J.C. (2006) Sustaining water resources in South East England. Atmospheric Science 671 Letters 7(3), 75-77. 
672 Rosa, I.C., Pereira, J.L., Gomes, J., Saraiva, P.M., Gonçalves, F. and Costa, R. (2011) The Asian 673 clam Corbicula fluminea in the European freshwater-dependent industry: A latent threat or a 674 friendly enemy? Ecological Economics 70(10), 1805-1813.

675 Roy, H., Peyton, J., Aldridge, D.C., Bantock, T., Blackburn, T., Bishop, J., Britton, R., Clark, P., 676 Cook, E., Dehnen-Schmutz, K., Dines, T., Dobson, M., Edwards, F., Harrower, C., Harvey, M., 677 Minchin, D., Newman, J., Noble, D., Parrott, D., Pocock, M., Preston, C., Roy, S., Salisbury, A., 678 Schonrogge, K., Sewell, J., Shaw, R.E., Stebbing, P., Stewart, A. and Walker, K. (2014) Horizon679 scanning for invasive alien species with the potential to threaten biodiversity in Great Britain. 680 Global Change Biology 20(12), 3859-3871.

681 Seaver, R.W., Ferguson, G.W., Gehrmann, W.H. and Misamore, M.J. (2009) Effects of 682 ultraviolet radiation on gametic function during fertilization in zebra mussels (Dreissena 683 polymorpha). Journal of Shellfish Research 28(3), 625-633.

684 Spooner, D. and Vaughn, C. (2008) A trait-based approach to species' roles in stream 685 ecosystems: climate change, community structure, and material cycling. Oecologia 158(2), $686 \quad 307-317$.

687 Stefan, H.G. and Preud'homme, E.B. (1993) Stream temperature estimation from air 688 temperature. Journal of the American Water Resources Association 29(1), 27-45.

689 Strayer, D.L. (1991) Projected distribution of the zebra mussel, Dreissena polymorpha, in North 690 America. Canadian Journal of Fisheries and Aquatic Sciences 48(8), 1389-1395.

691 Urban, D.L., Minor, E.S., Treml, E.A. and Schick, R.S. (2009) Graph models of habitat mosaics. 692 Ecology letters 12(3), 260-273.

693 Verbrugge, L.H., Schipper, A., Huijbregts, M.J., Van der Velde, G. and Leuven, R.E.W. (2012) 694 Sensitivity of native and non-native mollusc species to changing river water temperature and 695 salinity. Biological Invasions 14(6), 1187-1199.

696 Vörösmarty, C.J., McIntyre, P.B., Gessner, M.O., Dudgeon, D., Prusevich, A., Green, P., Glidden, 697 S., Bunn, S.E., Sullivan, C.A. and Reidy Liermann, C. (2010) Global threats to human water 698 security and river biodiversity. Nature 467(7315), 555.

699 Zamora-Marín, J.M., Zamora-López, A., Sánchez-Pérez, A., Torralva, M. and Oliva-Paterna, F.J. 700 (2018) Establecimiento de la almeja asiática Corbicula fluminea (Müller, 1774) en la cuenca del 701 río Segura (SE Península Ibérica). Limnetica 37(1), 1-7.

702 Zieritz, A., Gallardo, B. and Aldridge, D.C. (2014) Registry of non-native species in the Two Seas 703 region countries (Great Britain, France, Belgium and the Netherlands). NeoBiota 23, 65-80. 
bioRxiv preprint doi: https://doi org/101101/356923; this version posted June 27, 2018. The copyright holder for this preprint (which was not certified by peer review) is the author/funder, who has granted bioRxiv a license to display the preprint in perpetuity. It is made available under aCC-BY-NC-ND 4.0 International license.

706

707

708

\section{Tables}

Table 1. River characteristics at 16 points of interest located regularly at 30-km distance in the Severn and the

Thames Rivers (see Fig. 1). Results from Kruskal-Wallis performed between rivers are reported in the last row.

\begin{tabular}{|c|c|c|c|c|c|c|c|c|}
\hline River & $\begin{array}{l}\text { Width } \\
\text { (m) }\end{array}$ & $\begin{array}{l}\text { Depth } \\
\text { (cm) }\end{array}$ & $\begin{array}{l}\text { Alkalinity } \\
\text { (ppm) }\end{array}$ & $\begin{array}{l}\text { Silt } \\
\& \text { clay } \\
(\%)\end{array}$ & $\begin{array}{l}\text { Sand } \\
\text { (\%) }\end{array}$ & $\begin{array}{l}\text { Pebbles } \\
\& \\
\text { boulders } \\
(\%)\end{array}$ & $\begin{array}{l}\text { Discharge } \\
\left(\mathrm{m}^{3} / \mathrm{s}\right)\end{array}$ & $\begin{array}{l}\text { Ecological } \\
\text { Status }\end{array}$ \\
\hline 1-Thames & 55.30 & 260.00 & 182.00 & 4 & 5 & 90 & $40-80$ & Poor \\
\hline 2-Thames & 3.20 & 31.67 & 300.00 & 60 & 23 & 12 & $<0.31$ & Moderate \\
\hline 3-Thames & 11.60 & 19.33 & 168.10 & 15 & 7 & 73 & $0.31-0.62$ & Poor \\
\hline 4-Thames & 3.20 & 31.67 & 300.00 & 60 & 23 & 12 & $<0.31$ & Moderate \\
\hline 5-Thames & 1.40 & 8.00 & 240.00 & 50 & 47 & 3 & $<0.31$ & Moderate \\
\hline 6-Thames & 5.80 & 46.67 & 169.00 & 8 & 75 & 15 & $1.25-2.5$ & Poor \\
\hline 7-Thames & 1.50 & 15.00 & 230.00 & 94 & 5 & 0 & $<0.31$ & Poor \\
\hline 8-Thames & 1.70 & 8.67 & 215.00 & 17 & 43 & 40 & $<0.31$ & Moderate \\
\hline 9-Severn & 30.00 & 50.00 & 105.27 & 100 & 0 & 0 & $>80$ & Moderate \\
\hline 10-Severn & 26.70 & 233.33 & 119.10 & 78 & 8 & 13 & $>80$ & Moderate \\
\hline 11-Severn & 50.00 & 300.00 & 178.00 & 100 & 0 & 0 & $40-80$ & Moderate \\
\hline 12-Severn & 38.70 & 25.00 & 95.80 & 2 & 0 & 37 & $40-80$ & Moderate \\
\hline 13-Severn & 30.70 & 24.33 & 18.10 & 0 & 7 & 33 & $10-20$ & Moderate \\
\hline 14-Severn & 7.70 & 14.00 & 120.10 & 8 & 17 & 42 & $0.62-1.25$ & Moderate \\
\hline 15-Severn & 8.50 & 121.67 & 59.80 & 77 & 0 & 20 & $<0.31$ & Poor \\
\hline 16-Severn & 0.90 & 3.33 & 146.00 & 0 & 30 & 70 & $<0.31$ & Moderate \\
\hline $\begin{array}{l}\text { Kruskal-Wallist } \\
\text { Test (Chi, P) }\end{array}$ & $\begin{array}{l}2.48 \\
\text { n.s. }\end{array}$ & $\begin{array}{l}0.54 \text {, } \\
\text { n.s. }\end{array}$ & $\begin{array}{l}9.94 \\
0.001\end{array}$ & $\begin{array}{l}0.00 \\
\text { n.s. }\end{array}$ & $\begin{array}{l}3.84 \\
0.04\end{array}$ & $\begin{array}{l}0.10 \text {, } \\
\text { n.s. }\end{array}$ & 3.50, n.s. & 2.45, n.s. \\
\hline
\end{tabular}

709 


\section{$711 \quad$ 10. Figures}

712 Figure 1. Study area located in the Severn and Thames river catchments in the south of Great Britain. The

713 presence of three invasive and three native species is shown. Points of interest, located at regular $30-\mathrm{km}$ intervals in

714 each river, represent potential withdrawal and discharge river sections for an inter-basin water transfer.

715

716 Figure 2. Climate suitability and landscape connectivity for three invasive species in the Severn and Thames

717 river catchments. An inter-basin water transfer would increase propagule pressure, particularly in those areas with

718 a high connectivity. Climate Suitability Models ( $A, C$ and $E$ ) indicate the probability of establishment if the species is

719 introduced. White dots indicate locations already invaded by each species. Landscape Connectivity Analysis (B, D

720 and F) indicates preferential connectivity pathways between potential withdrawal and discharge sections (points of

721 interest) in both catchments.

722

Figure 3. Cumulative climate suitability for three invasive species (A), three native species (B) and their overlap

(C) in the Severn and Thames river catchments. Points of interest, located at regular 30-km intervals in each river, represent potential withdrawal and discharge river sections for an inter-basin water transfer.

Figure 4. Results from regional species distribution models used to calculate habitat suitability for invasive and native species. A: Bars represent the mean and SD of the contribution of variables to regional models for invasive (red bars) and native (blue bars) species. B and C: cumulative regional suitability for two in vasive species and three native species in the Severn and Thames river catchments. Points of interest, located at regular 30-km intervals in each river, represent potential withdrawal and discharge river sections for an inter-basin water transfer. 


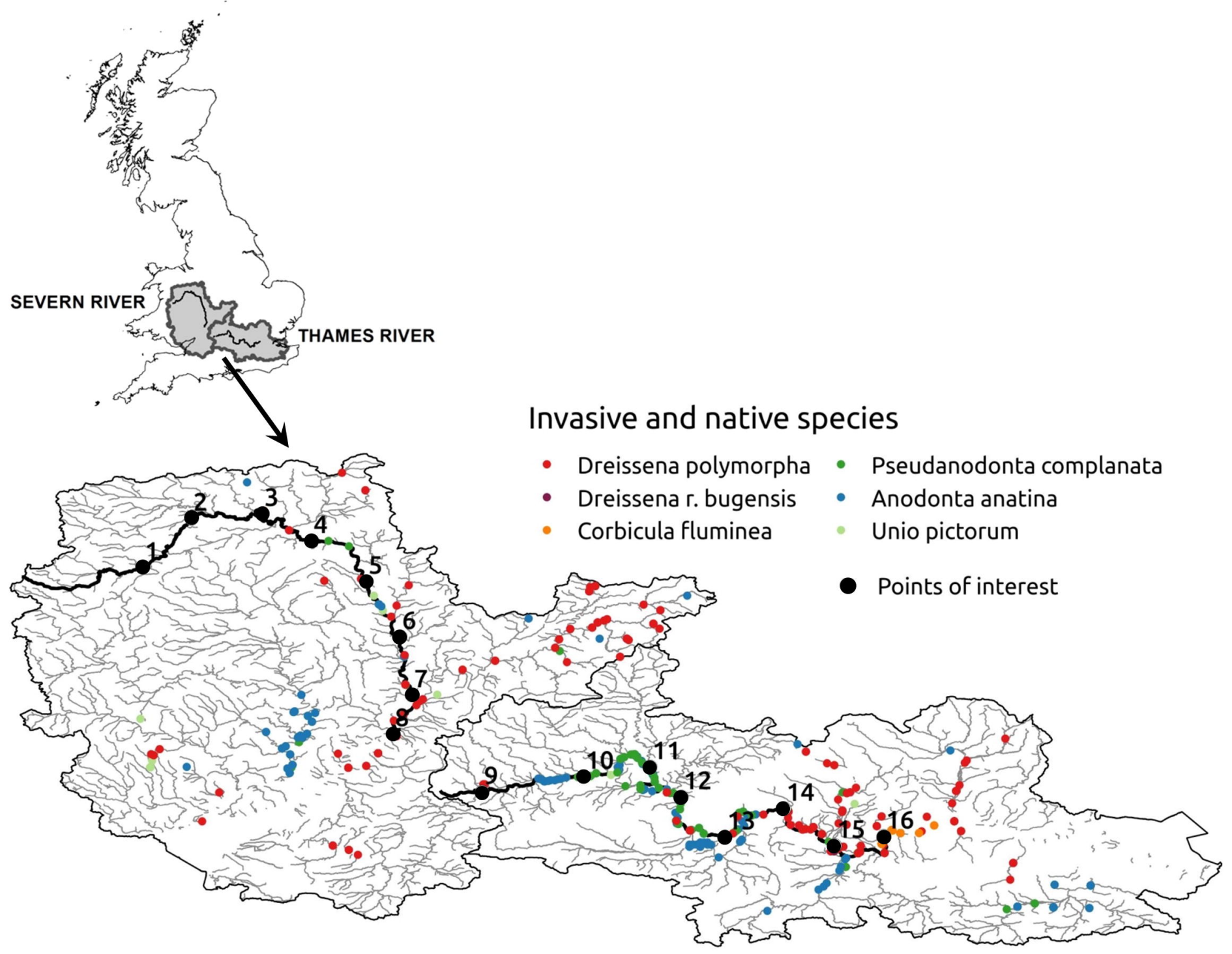




\section{A) Dreissena polymorpha}

\section{Climate suitability}

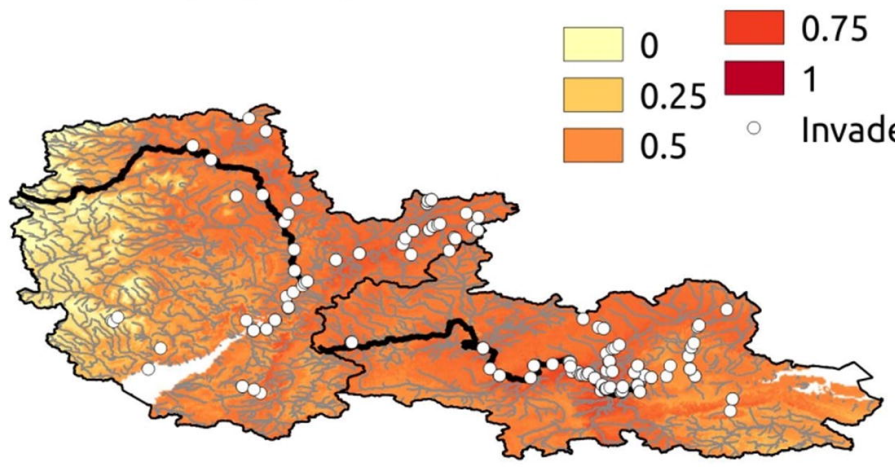

C) Dreissena r. bugensis

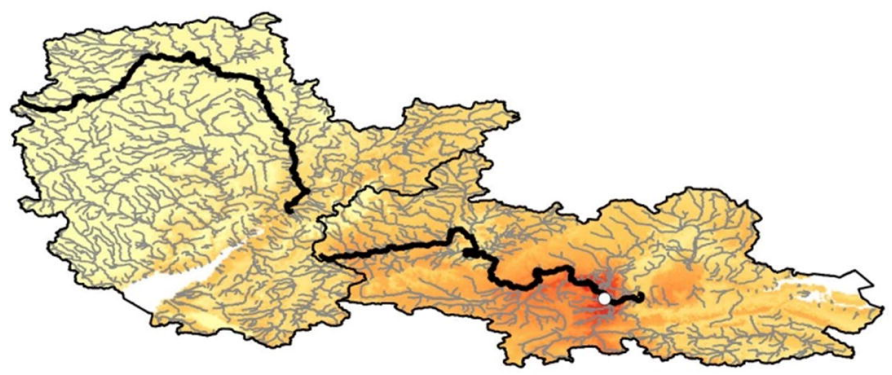

E) Corbicula fluminea

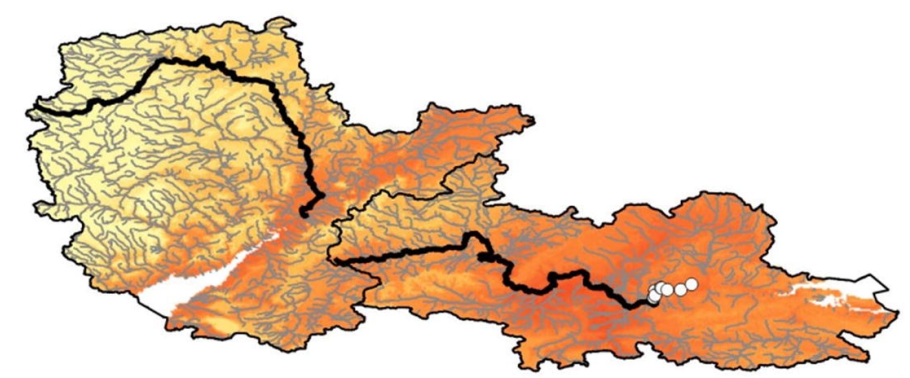

B) Landscape Connectivity

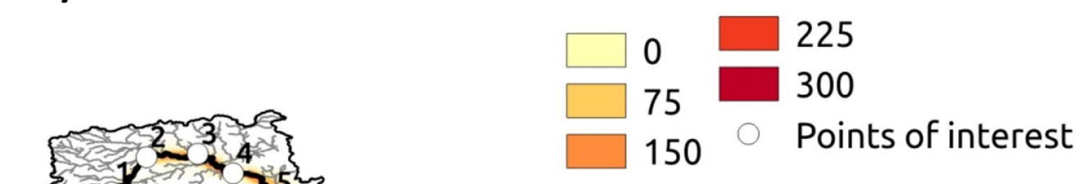

D)

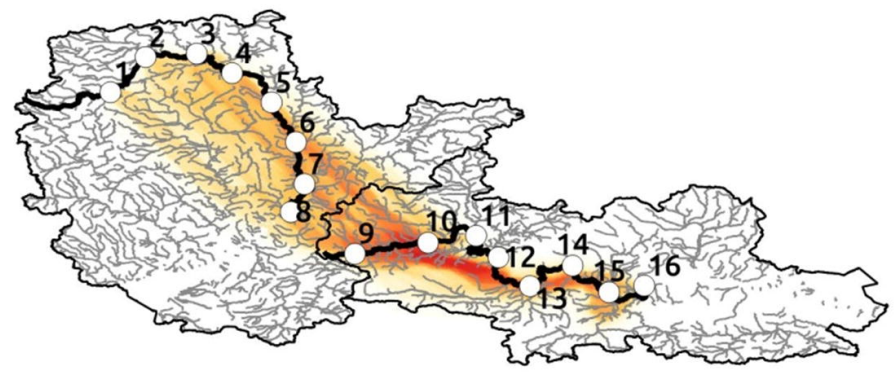

F)

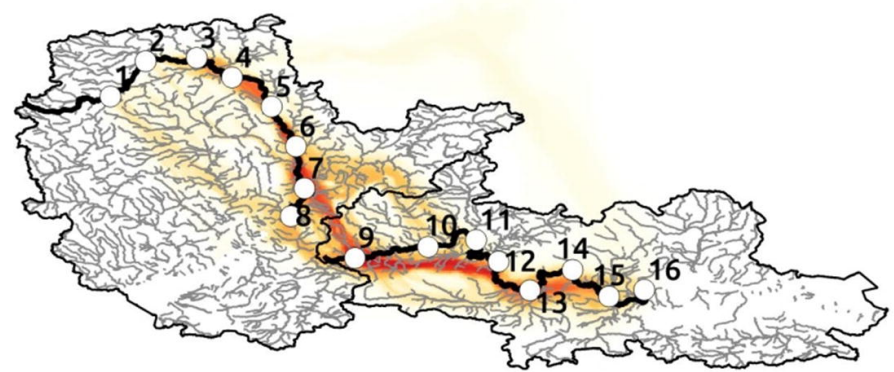



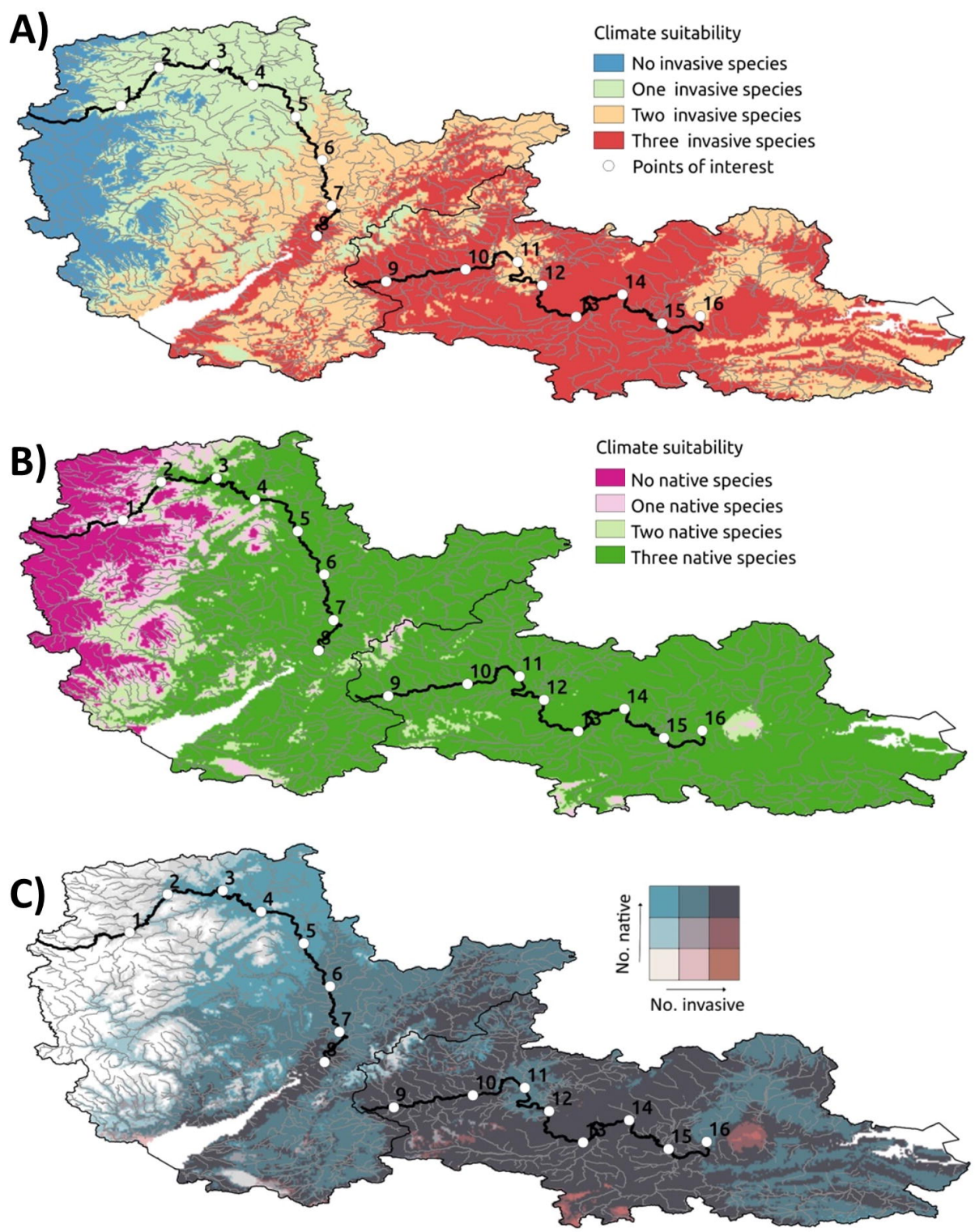
A)

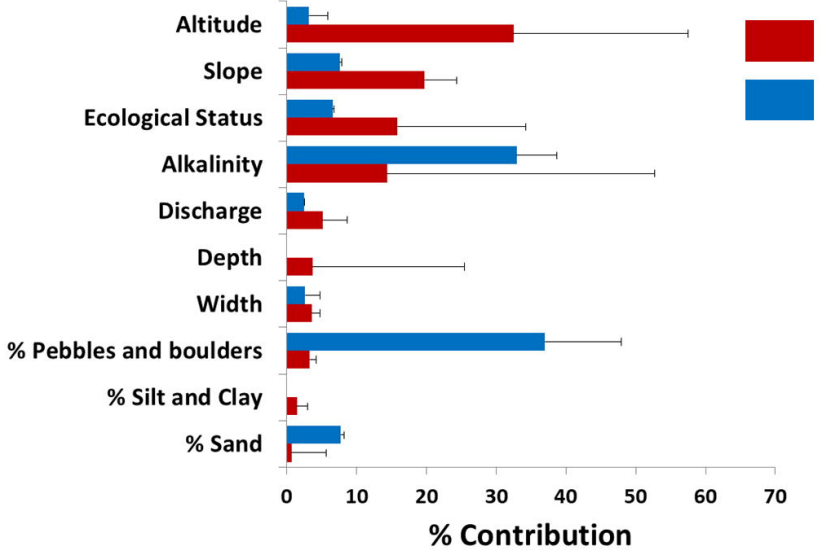

Invasive species Native species

\section{$\%$ Contribution}

B)
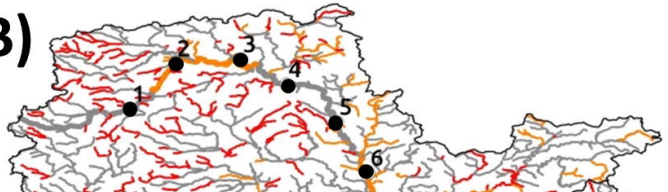

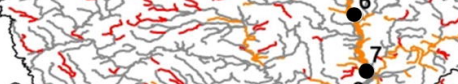

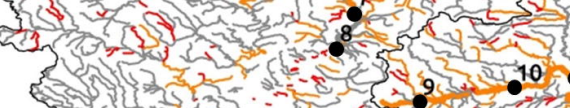

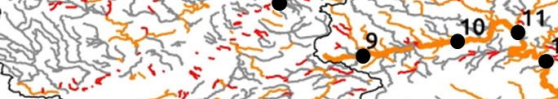

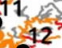

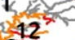

C)
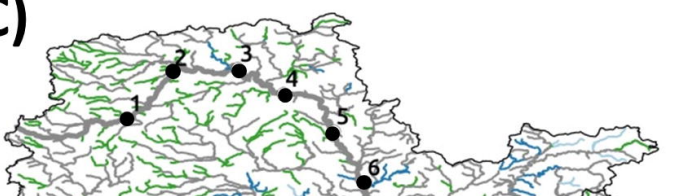

is 군

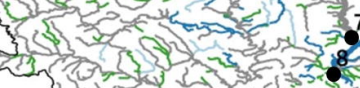
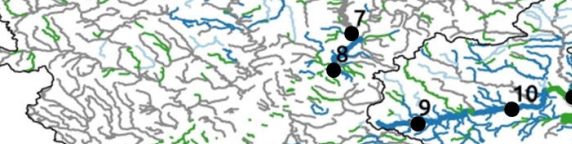

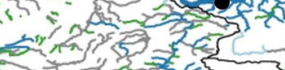
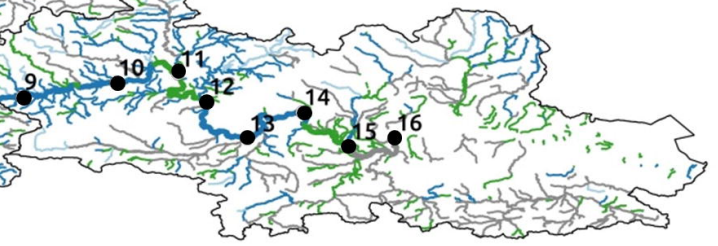

Regional suitability

- No native species

- One native species

Two native species

Three native species

- Points of interest 